\title{
DNA Damage Repair and DNA Methylation in the Kidney
}

\author{
Kaori Hayashi Akihito Hishikawa Hiroshi Itoh \\ Department of Internal Medicine, School of Medicine, Keio University, Tokyo, Japan
}

\section{Keywords}

DNA damage repair · Epigenetics · Podocytes

\begin{abstract}
The DNA repair system is essential for the maintenance of genome integrity and is mainly investigated in the areas of aging and cancer. The DNA repair system is strikingly celltype specific, depending on the expression of DNA repair factors; therefore, different DNA repair systems may exist in each type of kidney cell. Importance of DNA repair in the kidney is suggested by renal phenotypes caused by both genetic mutations in the DNA repair pathway and increased stimuli of DNA damage. Recently, we reported the importance of DNA double-strand break repair in glomerular podocytes and its involvement in the alteration of DNA methylation status, which regulates podocyte phenotypes. In this review, we summarize the roles of the DNA repair system in the kidneys and possible associations with altered kidney DNA methylation, which have been infrequently reported together. Investigations of DNA damage repair and epigenetic changes in the kidneys may achieve a profound understanding of kidney aging and diseases.
\end{abstract}

(c) 2019 S. Karger AG, Basel

\section{Summary of the DNA Damage Repair System}

DNA damage is caused by various stresses, including exogenous stress, such as UV radiation and chemicals, and endogenous stress, such as reactive oxygen species,
DNA replication errors, spontaneous reactions, and mechanical stress $[1,2]$. Chronic stimulation by these stresses induces DNA damage, which is linked to aging and various diseases [3]. Eukaryotes have a DNA repair system in response to DNA damage to maintain genome integrity for survival. Various types of DNA damage exist, including double-strand breaks (DSBs), base adducts, interstrand crosslinks, and mismatch. Base adducts include oxidative and alkylating lesions, some of which may be mutagenic such as 7,8-dihydro-8-oxoguanine or toxic [4]. Interstrand crosslinks are toxic DNA lesions preventing transcription and replication by inhibition of DNA strand separation. Base mismatch arises during DNA replication and recombination. Injured DNA are repaired through DNA repair pathways, including nonhomologous end joining (NHEJ), homologous recombination (HR), base excision repair (BER), nucleotide excision repair (NER), translesion synthesis and mismatch repair (MMR), as shown in Figure $1[1,4]$.

In particular, DNA DSBs are biologically important since their repair is intrinsically more difficult than other types of DNA damage [5]. DNA DSBs are repaired by HR during cell division or by NHEJ in nondividing conditions. The Mre11-Rad50-Nijmegen breakage syndrome protein 1 complex is involved in both the NHEJ and HR pathways for DNA DSB sensing. NHEJ is a dominant pathway for repairing DNA DSBs in eukaryotes. The process of NHEJ is divided into 3 steps as follows: end bridging, end processing, and end joining to resect damaged DNA, fill in new DNA, and restore integrity to the DNA strands (Fig. 2). When a DSB occurs in vertebrates, a

\section{KARGER}

(c) 2019 S. Karger AG, Basel

E-Mail karger@karger.com

www.karger.com/ajn
Kaori Hayashi, MD, PhD

Department of Internal Medicine

School of Medicine, Keio University

35 Shinanomachi, Shinjuku-ku, Tokyo 160-8582 (Japan)

E-Mail kaorihayashi@keio.jp 


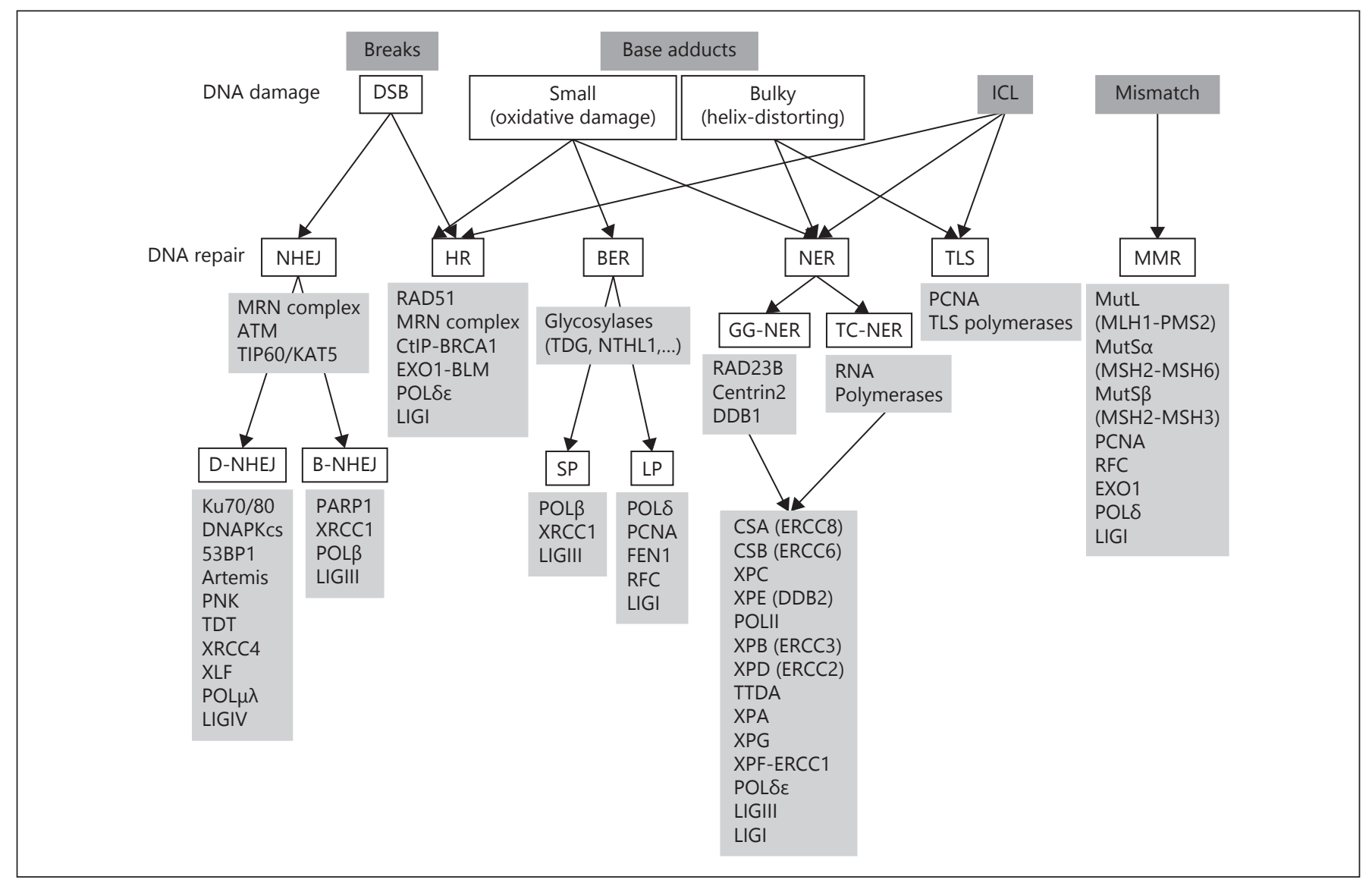

Fig. 1. DNA damage repair pathways and the related factors. DNA DSB is a cytotoxic injury induced by radiation or chemicals. Base adducts is a mutagenic injury typically in cancer-causing chemicals. ICLs are covalent links of DNA duplexes, preventing transcription and replication. Base mismatch arises during DNA replication and recombination. DSB, double-strand break; ICL, interstrand crosslink;D-NHEJ,DNA-PKcs-dependent nonhomologous end joining; B-NHEJ, a backup to DNA-PKcs-dependent nonhomologous end joining; $\mathrm{HR}$, homologous recombination; $\mathrm{BER}$, base excision repair; NER, nucleotide excision repair; GG-NER, global genome NER; TC-NER, transcription-coupled NER; TLS, translesion synthesis; MMR, mismatch repair; SP, short-patch; LP, long-patch; MRN complex, meiotic recombination 11 homolog 1 (Mre11)-Rad50-Nijmegen breakage syndrome protein 1 (Nbs1) complex; ATM, ataxia telangiectasia mutated; KAT5, lysine acetyltransferase 5; DNA-PKcs, DNA-dependent protein kinase catalytic subunit; 53BP1, p53-binding protein 1; PNK, polynucleotide

dimeric protein complex Ku70/80 X-ray repair crosscomplementing protein (XRCC6/XRCC5) first binds the damaged DNA end, and the nuclease complex of Artemis and DNA-dependent protein kinase catalytic subunit (DNA-PKcs), some polymerases, including DNA polymerase $\lambda$ and $\mu$, and the ligase (LIG) complex of XRCC4, XRCC4-like factor, and DNA LIG IV are recruited [2]. kinase; TDT, terminal deoxynucleotidyl transferase; XRCC, X-ray repair cross-complementing protein; XLF, XRCC4-like factor; POLII, RNA polymerase II; POL $\mu, \lambda, \beta, \delta, \varepsilon$, DNA polymerase $\mu$, $\lambda, \beta, \delta, \varepsilon$; LIG IV, III, I, DNA ligase IV, III, I; PARP1, poly(ADPribose) polymerase 1; CtIP, C-terminal-binding protein (CTBP)interacting protein; BRCA1, breast cancer 1; EXO1, exonuclease 1; BLM, Bloom's syndrome protein; TDG, Thymine-DNA glycosylase; NTHL1, nth like DNA glycosylase 1; PCNA, proliferating cell nuclear antigen; FEN1, flap structure-specific endonuclease 1; XPC, XPE, XPB, XPD, XPA, XPG, XPF, Xeroderma pigmentosum, complementation group C, E, B, D, A, G, F protein; DDB1, 2, damage-specific DNA-binding protein 1, 2; RFC, replication factor C; ERCC8, 6, 3, 2, 1, excision repair 8, 6, 3, 2, 1; CSA, B, Cockayne syndrome A, B ortholog; TTDA, L(+)-tartrate dehydratase subunit alpha, MLH1, mutL homolog 1; PMS2, PMS1 homolog 2, $\mathrm{MSH}$, 6, 3, mutS homolog 2, 6, 3.

This repair pathway is called the DNA-PKcs-dependent NHEJ (D-NHEJ) [2, 6]. Recent studies have demonstrated that there is an alternative form of NHEJ functioning as a backup to D-NHEJ, which is called B-NHEJ. In BNHEJ, histone $\mathrm{H} 1$ and poly(ADP-ribose) polymerase1 helps align the DNA ends prior to ligation without $\mathrm{Ku}$ and DNA-PKcs, followed by end processing and ligation 
Fig. 2. Scheme of D-NHEJ and B-NHEJ pathways in DNA DSB repair. D-NHEJ, DNA-PKcs-dependent nonhomologous end joining; B-NHEJ, a backup to DNAPKcs-dependent nonhomologous end joining; DNA-PKcs, DNA-dependent protein kinase catalytic subunit; 53BP1, p53-binding protein 1; MRN complex, meiotic recombination 11 homolog 1 (Mre11)-Rad50Nijmegen breakage syndrome protein 1 (Nbs1) complex; XRCC4, 1, X-ray repair cross-complementing protein 4, 1; XLF, XRCC4-like factor; PARP1, poly(ADP-ribose) polymerase 1; CtIP, C-terminal-binding protein (CTBP)-interacting protein; DSB, double strand break.

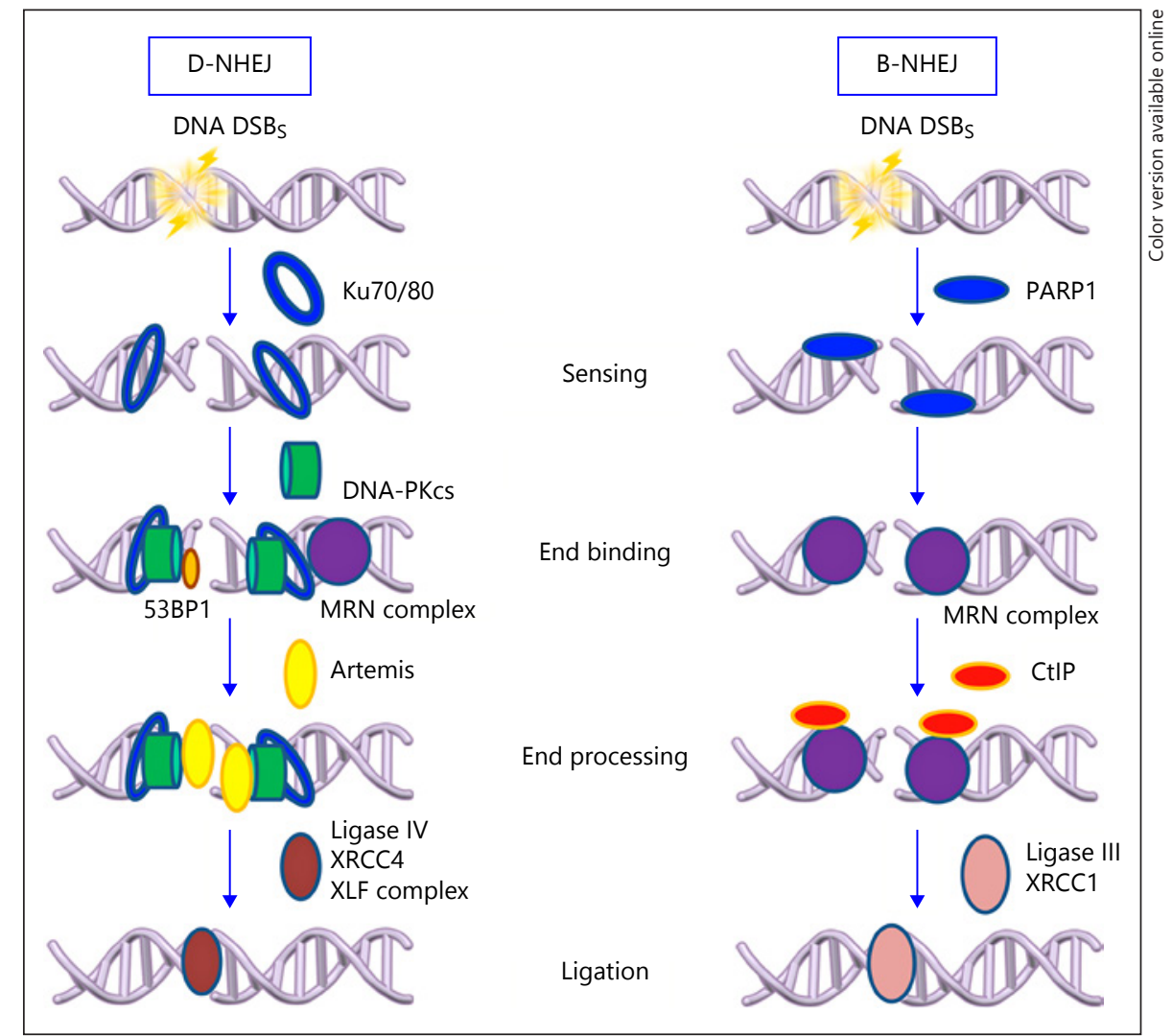

with C-terminal-binding protein-interacting protein, XRCC1, and DNA LIGIII $[2,6]$. NHEJ is critical not only for the repair of DSBs induced by stresses but also for the repair of physiologic DSBs created during variable (diversity) joining $\mathrm{V}(\mathrm{D}) \mathrm{J}$ recombination and class switch recombination. Therefore, patients lacking normal NHEJ are not only sensitive to ionizing radiation but also severely immune deficient [2].

BER is the primary DNA repair pathway that corrects base lesions and facilitates the repair via 2 pathways as follows: short-patch (a single nucleotide repair) and long-patch (at least 2 nucleotides repair) $[7,8]$. The BER pathway is initiated by glycosylases, such as thymineDNA glycosylase by excision of damaged bases, and is followed by strand incision, gap-filling, and ligation; these processes are mediated by DNA polymerase $\beta$, XRCC1, and LIGIII in short-patch or by DNA polymerase $\delta \varepsilon$, flap endonuclease-1, proliferating cell nuclear antigen, replication factor C, and DNA LIGI in longpatch $[7,8]$.

NER can be subdivided into several subpathways, including global genome repair and transcription-coupled repair (TCR, TC-NER) [4, 9]. TCR is conducted in the transcribed strand of active genes, which are nec- essary to be repaired with higher priority. Global genome repair covers the component of NER that is not TCR.

MMR is conducted by MutSa homolog (MSH2-MSH6 heterodimer) or MutS $\beta$ (MSH2-MSH3 heterodimer), MutL homolog 1-PMS1 homolog 2 heterodimer, proliferating cell nuclear antigen, replication factor $\mathrm{C}$, and human exonuclease 1 [7].

\section{Renal Phenotypes in Genetic Deletion of DNA Repair Pathways}

Genetic deletion of these DNA repair pathways causes progeria, cancer, or immunodeficiency as summarized in Table 1. Precise mechanism of each repair pathway is not completely elucidated, and several DNA repair-deficient human syndromes are expected to remain undiscovered.

Renal phenotypes with genetic mutations of DNA repair factors may suggest the possible roles of the DNA damage repair system in kidney homeostasis. Kidney is classified as a slowly proliferative organ, which can divide in response to damages, and quite different from prolif- 
Table 1. Genetic deletion of DNA repair factors and renal phenotypes

\begin{tabular}{|c|c|c|c|c|}
\hline Mutated genes & Affected pathways & Syndrome & Phenotypes & Renal manifestations \\
\hline CSA (ERCC8) & TC-NER; GG-NER & CS type A & Progeria & $\begin{array}{l}\text { Nephrotic synd, RPGN; } \\
\text { glomerulosclerosis, hypertension [88], } \\
\text { GBM thickening [89] }\end{array}$ \\
\hline CSB (ERCC6) & TC-NER; GG-NER & CS type B & Progeria & $\begin{array}{l}\mathrm{Csa}^{-/-} \text {or } \mathrm{Csb}^{\mathrm{m} / \mathrm{m}} \text { mice: protect } \\
\text { from IR injury [26] }\end{array}$ \\
\hline XPB, XPD, TTDA & GG-NER, TC-NER & TTD & Progeria & $\begin{array}{l}\text { XP/TTD overlap: adult onset } \\
\text { kidney failure [90] }\end{array}$ \\
\hline CSB, XPD, XPG & TC-NER; GG-NER & COFS & Progeria & $\begin{array}{l}\text { Not mentioned (high expression } \\
\text { of XPG in human kidney [91] }\end{array}$ \\
\hline XPF/ERCC1 & TC-NER; GG-NER, ICL, HR & XPF-ERCC1 progeria (XFE) & Progeria & $\begin{array}{l}\text { Liver-specific Ercc1 TG Ercc1-/- } \\
\text { mice: proteinuria, ESRD [14] }\end{array}$ \\
\hline $\mathrm{XPC}$ & GG-NER & $\mathrm{XP}$ & Cancer & Not mentioned \\
\hline XPB, XPF, XPD, XPG & TC-NER; GG-NER & XP combined with CS (XPCS) & Progeria/cancer & Nephrotic syndrome [92] \\
\hline NTHL1 & BER & NTHL1 deficiency & Cancer & Not mentioned \\
\hline $\begin{array}{l}\text { PMS2, MLH1, MSH2, } \\
\text { MSH6, MLH3, MSH3 }\end{array}$ & MMR & Lynch syndrome, HNPCC & Cancer & Not mentioned \\
\hline FANC, BRCA2, FAN1 & ICL repair & Fanconi anemia & Progeria/cancer & $\begin{array}{l}2 / 30 \text { patients had CKD, } 14 / 30 \text { patients } \\
\text { had anatomical abnormalities of the } \\
\text { kidneys [93] } \\
\text { Karyomegalic interstitial ephritis } \\
\text { linking to chronic kidney failure [94] }\end{array}$ \\
\hline BRCA1 & DSB repair $(\mathrm{HR})$ & Breast cancer 1 , early onset & Cancer & Renal cell carcinoma [95] \\
\hline BRCA2 & DSB repair $(\mathrm{HR})$ & Breast cancer 2, late onset & Cancer & $\begin{array}{l}\text { Zebrafish BRCA2: essential for } \\
\text { pronephros development [96] }\end{array}$ \\
\hline ATM & DSB repair & $\mathrm{AT}$ & Progeria/cancer & Not mentioned \\
\hline MRE11, PCNA & DSB repair, BER & ATLD & Progeria/cancer & Not mentioned \\
\hline $\begin{array}{l}\text { MRE11, ZNF423, } \\
\text { CEP164SDCCAG8 }\end{array}$ & DSB repair & NPHP-RC & Degenerative disorder & Renal fibrosis, ESRD [22-24] \\
\hline NBS1 & DSB repair & NBS & Progeria/cancer & $\begin{array}{l}\text { Congenital renal anomalies } \\
\text { (hypoplasia/aplasia, horseshoe } \\
\text { or double kidney, } \\
\text { ectopic/dystopic kidneys) are } \\
\text { relatively frequent }\end{array}$ \\
\hline LIGIV & DSB repair (NHEJ) & LIG4 syndrome, MPD & Cancer, (S)CID & Not mentioned \\
\hline XLF (Cernunnos) & DSB repair (NHEJ) & $\begin{array}{l}\text { XLF/Cernunnos } \\
\text { immunodeficiency }\end{array}$ & Cancer, (S)CID & Not mentioned \\
\hline Artemis (DCLRE1C) & DSB repair (NHEJ) & ARTEMIS deficiency, ART-SCID & Cancer, (S)CID & Not mentioned \\
\hline DNA-PKcs & DSB repair $(\mathrm{NHEJ})$ & DNA-PKcs deficiency & Cancer, (S)CID & Not mentioned \\
\hline XRCC4 (XPF) & DSB repair (NHEJ) & MPD & Progeria & Not mentioned \\
\hline
\end{tabular}

(S)CID, (severe) combined immunodeficiency; RPGN, rapid progressive glomerulonephritis; IR, ischemic reperfusion; ERCC, excision repair; CSA, Cockayne syndrome A; XPC, XPB, XPF, XPD, XPG, Xeroderma pigmentosum, complementation group C, B, F, D, G, protein; NTHL1, nth like DNA glycosylase 1; PMS2, PMS1 homolog 2; MLH1, mutL homolog 1; BRCA2, breast cancer 2; ATM, ataxia telangiectasia mutated; MRE11, meiotic recombination 11 homolog; NBS1, Nijmegen breakage syndrome protein 1; XLF, XRCC4-like factor; DNA-PKcs, DNA-dependent protein kinase catalytic subunit; XRCC4, X-ray repair cross-complementing protein 4; TC-NER, transcription-coupled nucleotide excision repair; GG-NER, global genome NER; BER, base excision repair; MMR, mismatch repair; ICL, interstrand crosslinks; DSB, double strand breakl; CS, Cockayne syndrome; TTD, trichothiodystrophy; COFS, Cerebro-oculo-facio-skeltal syndrome; HNPCC, Hereditary non-polyposis colorectal cancer; AT, Ataxia Telangiectasia; ATLD, Ataxia Telangiectasia-like disorder; NPHP-RC, Nephronophthisis-related ciliopathies; LIG4, DNA ligase 4; MPD, microcephalic primordial dwarfism; CKD, chronic kidney disease; HR, homologous recombination. 
erative organs, including skin, guts, myeloid, and testis. Genetic mutation in DNA repair factors causes malignancies in proliferative organs or degenerative manifestations in slowly- or nonproliferative organs, such as liver, kidney, and brain, if the individual escape from early death due to malignancy or severe immunodeficiency. If a repair factor is essential for kidney development, defect of the factor causes lethality, or anatomical renal abnormalities. DNA repair-deficient syndromes without kidney manifestations may indicate several possibilities. If deletion of a DNA repair pathway is lethal or causes malignancy early in life, kidney failure may be masked. Another possibility is the different degree of contribution to kidney DNA repair among the repair pathways. In addition, kidney is consisted of various cell types with different proliferative capacity; for instance, tubular cells and collecting duct cells are slowly proliferative while podocytes are basically nonproliferative. Therefore, it is distinctive that cell dysfunction caused by an impaired DNA damage repair pathway can induce various manifestations in diseases.

Deletion of the NER pathway causes accelerated aging with shortened lifespan with renal abnormalities and neurological impairment $[10,11]$; examples include the Cockayne syndrome, which is caused by mutations in excision repair (ERCC)6 (Cockayne syndrome B, CSB) or ERCC8 (Cockayne syndrome A, CSA), trichothiodystrophy caused by mutations in ERCC2 (XPD), ERCC3 (XPB), or L(+)-tartrate dehydratase subunit alpha, and XPF-ERCC1 progeria, which is caused by dysfunction of the XPF-ERCC1 heterodimer [12,13]. ERCC1-knockout mice suffer from severe neurological abnormalities and die before 3-5 weeks of age. A modified ERCC1 knockout mouse model expressing a liver-specific ERCC1 rescue transgene to prevent hepatic insufficiency develops proteinuria, segmental glomerulosclerosis, and considerable nuclear pleomorphism in proximal tubules at 3 weeks of age and progresses to end-stage renal failure [14]. Therefore, DNA damage repair through the NER pathway is considered to play a possible role in renal function.

On the other hand, a germline homozygous mutation in the BER gene nth like DNA glycosylase 1, a DNA glycosylase, causes colorectal malignancy, but renal complications are not mentioned [15]. Constitutional MMR deficiency, due to biallelic mutations of MMR genes, results in lymphoblastic T cell lymphoma, colorectal adenocarcinoma, and urinary tract tumors occurring mostly in childhood [16].

DNA DSBs are repaired through HR during cell division or NHEJ, and NHEJ is the dominant pathway in eu- karyotes. Mutations in NHEJ-related genes, including DNA LIG IV, XRCC4-like factor-Cernunnos, Artemis, or DNA-PKcs, have been identified in patients with a malignancy and/or combined immunodeficiency since the NHEJ pathway is essential for $\mathrm{V}(\mathrm{D}) \mathrm{J}$ recombination [17]. Recently, patients with mutations in XRCC4 were reported to have symptoms similar to those of Cockayne syndrome, as previously described above $[18,19]$. The Ku70/ Ku80 mutation in patients has not been identified, although Ku80-knockout mice develop renal tubular anisokaryosis and cortical and medullary atrophy [20]. Anatomical renal abnormalities are reported in Nijmegen breakage syndrome, which is caused by a mutation of $\mathrm{Ni}$ jmegen breakage syndrome protein 1 [21]. Nephronophthisis and related ciliopathies are recently demonstrated to show altered DNA DSB repair pathway in humans [22, 23], and Apoptosis Antagonizing Transcription Factor is a key regulator in the mice nephronophthisis and related ciliopathies model [24]. In addition, polymorphic allele of XRCC1 gene is recently reported to be significantly related with type 2 diabetes and diabetic nephropathy [25].

Several benefits associated with DNA repair deficiency have also been reported. Deficiency of a NER factor CSA or CSB in mice showed a protective effect against ischemic-reperfusion injury [26]. In addition, overexpression of nth like DNA glycosylase 1 glycosylase, a BER factor, causes genomic instability and cancer [27]. These results suggest that unrepaired DNA damage leads to either detrimental effects or beneficial adaptive changes depending on the tissue or cell types, which may contribute to the specificity of disease phenotypes. We summarize genetic mutations of DNA repair pathways and renal phenotypes in Table 1.

\section{DNA Damage and Repair in Kidney Diseases}

In addition to renal phenotypes of genetic deletion of DNA repair pathways, changes in the environment of kidney DNA damage repair, including increased DNA damage induced by activated renin angiotensin system, sepsis, and drugs, and impaired DNA repair caused by decreased expression of DNA repair factors, are reported in kidney diseases. Angiotensin II and aldosterone, which are key players in chronic kidney disease (CKD) progression, can cause DNA damage such as DSBs and DNA base modification to 8-hydroxy-2'-deoxy-guanosine $[28,29]$. Increased DNA damage is also reported in acute kidney injury, including ischemia-reperfusion in- 
jury [30] and sepsis induced by Staphylococcus aureus [31]. It is not difficult to anticipate that drug-induced kidney injury was associated with the DNA damage response $[32,33]$. Puromycin aminonucleoside is a traditionally used agent to provoke minimal change nephrotic syndrome, and its effects are shown to be ascribed in part to DNA damage through reactive oxygen species in podocytes [34]. Of note, platinum drugs induce caspase-mediated apoptosis in tubular cells, while glomerular epithelial cells favor G2/M arrest when treated with equitoxic platinum doses $[35,36]$. These results may suggest that activation of the DNA damage repair system is strikingly agent- and cell type-specific being reflected by the different expression of DNA repair factors [35]. Kidney is consisted of various types of cells, including endothelial cells, mesangial cells and podocytes in a glomerulus, tubular cells, collecting duct cells, and fibroblasts. Although the repair capacity of these cells has not been clearly identified, different responses to therapy may indicate the variability of DNA repair capacity in each cell type as described above. Further examination in each kidney cell type is necessary to elucidate the importance of DNA damage repair in kidney diseases.

Renal cell carcinoma (RCC) is also relevant to estimate an importance of DNA repair factors in the kidney. Dalgliesh et al. [37] reported systematic sequencing of RCC, and some cases existed with mutations in DNA repair genes. These results suggest an importance of the DNA repair factors, especially in tubular cells that RCC is mainly originated from.

Interestingly, recent studies suggest that the state of nutrition is associated with an environment of DNA damage induction and repair [38], although the molecular mechanism has not been fully demonstrated. In diabetic nephropathy, which is a representative of nutritional and metabolic kidney disorders, DNA damage is increased such as serum 8-hydroxy-2'-deoxy-guanosine, a biomarker for oxidative DNA base modification, and DNA DSBs $[39,40]$. Recently, we have reported that the expression of the DNA DSB repair factor lysine acetyltransferase 5, Tip60 (KAT5) in podocytes is reduced in diabetic nephropathy in mouse models and humans. It has been revealed that high glucose causes not only increased induction of DNA DSBs but also decreased KAT5 expression, both of which lead to the accumulation of DNA DSBs [40].

In addition, DNA damage response-regulated kinases act on multiple substrates involved in glucose metabolism $[41,42]$; therefore, it is possible that the DNA damage re- sponse directly modulates certain aspects of energy metabolism and vascular physiology that are relevant to metabolic syndromes [43].

\section{Association of DNA DSB Repair with Altered DNA Methylation}

When damaged DNA is repaired, epigenetic marks are also reconstituted. Therefore, many epigenetic modulators are involved in the DNA repair process [44]. The accumulation of repair failures may cause changes in the epigenome, including histone modifications and DNA methylation, and in gene expression, as shown in Figure $3[45,46]$. In particular, DNA methylation is considered to be more stable than other types of epigenetic marks and may contribute to sustained changes in gene expression. Therefore, this review is focused on DNA methylation and DNA damage repair.

In tumorigenesis, DSBs induce DNA hypermethylation of the gene promoter region, which leads to decreased gene expression in in vitro models $[47,48]$. Several studies have suggested a relationship between DNA methylation and DNA damage repair. DNA methyltransferase 1 (DNMT1) is recruited to DSB sites where it colocalizes with the phosphorylated histone $\mathrm{H} 2 \mathrm{AX}(\gamma \mathrm{H} 2 \mathrm{AX})$ to silence the repaired gene [44]. Increased DNA methylation due to DNMT1 action may indicate epigenetic memory denoting a former damage $[46,47]$. Although DNMT1 is basically a maintenance methyltransferase that mainly methylates hemimethylated $\mathrm{CpG}$ sites during cell division, recent studies have revealed that it may also have a role in de novo methylation [49-51]. Previous reports have indicated that the cooperation of DNMT3 enzymes with DNMT1 achieved de novo DNA methylation more efficiently $[52,53]$. However, how DNA damage and repair can lead to the acquisition of aberrant DNA methylation is not still uncovered, especially in in vivo disease models.

\section{DNA DSB Repair and DNA Methylation in Kidney Podocytes}

Recently, growing evidence has suggested that epigenetic mechanisms are associated with kidney functions and diseases [54]. Combining the results of the GWAS metaanalysis and chromatin annotation maps, the importance of altered transcriptional regulation as a contributing mechanism to CKD has been demonstrated [55]. Moreover, recent epigenome-wide studies have identified the
86

Am J Nephrol 2019;50:81-91 DOI: $10.1159 / 000501356$
Hayashi/Hishikawa/Itoh 
Fig. 3. DNA damage, DNA methylation, and diseases. DNA DSBs followed by its sensing and signal transduction, cause either DNA repair or apoptosis depending on the severity of the damage. Impaired DNA repair may induce epigenetic changes such as altered DNA methylation, which leads to dysregulation of the genes and genomic instability. Me, DNA CpG methylation; PARP1, poly(ADP-ribose) polymerase 1; ATM, ataxia telangiectasia mutated; DSB, double strand break.

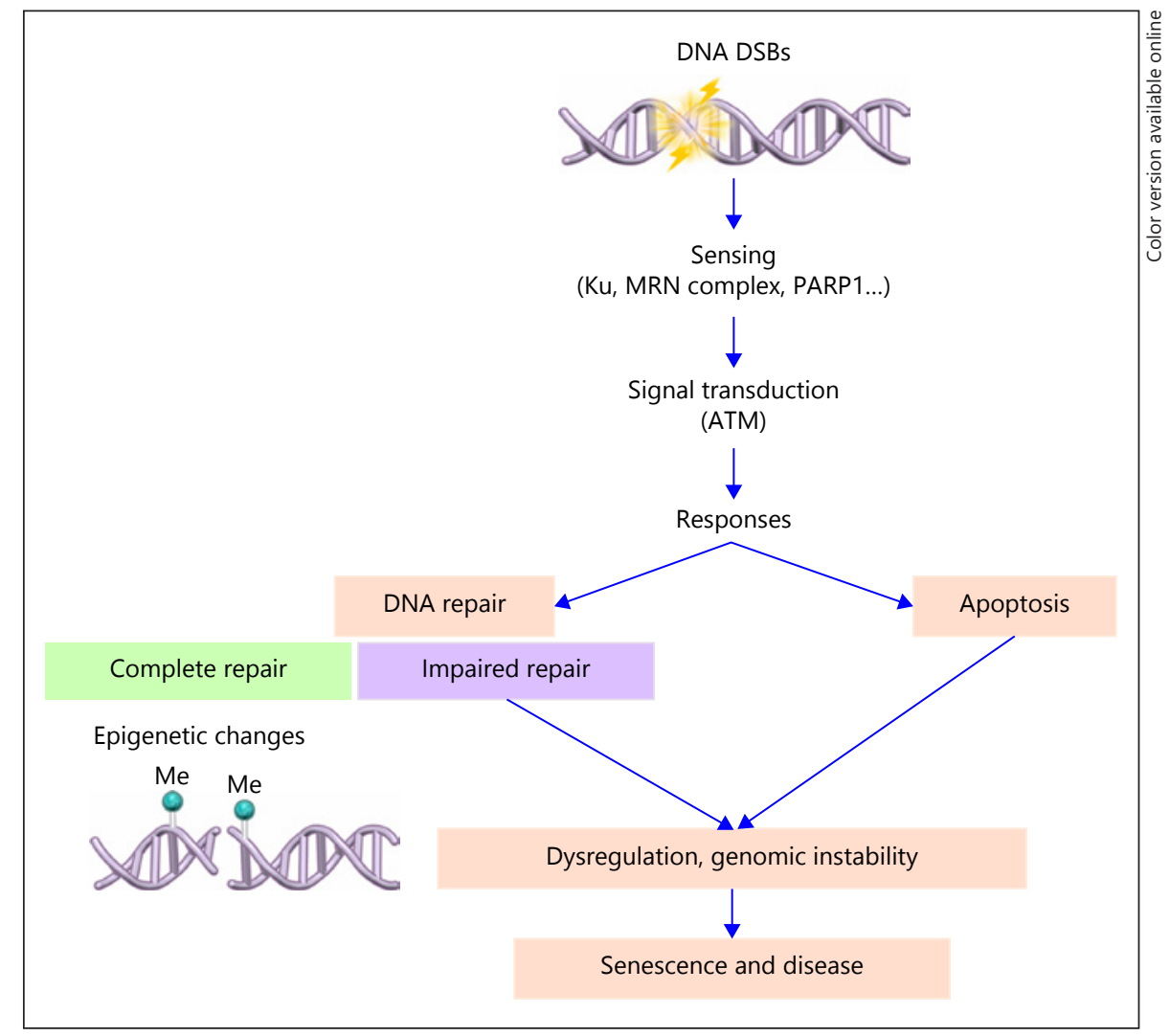

DNA methylation status associated with kidney function using saliva, whole blood or kidney specimen to analyze DNA methylation sites [56-60]. These results indicate that the investigation of epigenetic changes associated with CKD is important to understand the pathogenesis of CKD.

Possible roles of podocyte DNA methylation on CKD have been suggested in several in vivo models [61-63]. Altered DNA methylation causes phenotypical changes in podocytes $[64,65]$ and may lead to disruption of the slit membrane, proteinuria, and glomerulosclerosis. Podocytes, visceral epithelial cells, are terminally differentiated cells with a very low capacity of regeneration in adult mice under normal conditions [66, 67]; thus, it may contribute to the irreversibility of glomerulosclerosis and kidney aging [68]. Why and how changes in DNA methylation occur in podocytes without cell division? One of the mechanisms may be involved in the DNA damage repair system. It is reported that there are an estimated $10-50$ DSBs per day in dividing cells $[2,69]$. In nondividing cells, estimates of DSB frequency are difficult because they do not undergo metaphase. Therefore, it is not clear how many DSBs are induced in podocytes per day, although a large amount of DSB stress may exist around podocytes. Very few DNA DSB sites, which are shown as $\gamma \mathrm{H} 2 \mathrm{AX}$-positive areas, were observed in the kidneys of healthy young mice [40], suggesting that the DNA repair mechanism may be important in podocytes with physiological states.

Recently, it was reported that knockdown of podocyte KAT5 expression causes focal segmental glomerulosclerosis with increased DNA DSBs and phenotypical changes in podocytes [40], suggesting the importance of the KAT5-mediated DNA repair system for the maintenance of healthy podocytes. TIP60/KAT5 is a member of the MYST family of histone acetyltransferases. KAT5 activates ATM and DNA-PKcs, which is an important factor for NHEJ repair. Acetylation of $\gamma \mathrm{H} 2 \mathrm{AX}$ by KAT5 induces the initiation of ubiquitination of $\gamma \mathrm{H} 2 \mathrm{AX}$, which promotes the release of $\gamma \mathrm{H} 2 \mathrm{AX}$ from chromatin following DSBs [70].

Impaired KAT5-mediated DNA repair is associated with increased DNA methylation through DNMT1 and DNMT3B in podocytes. Although each deletion of DNMT1, DNMT3A, or DNMT3B in podocytes lacked phenotype development [71], double knockdown of DNMT1 and DNMT3B in cultured podocytes caused significant changes in DNA methylation of the nephrin 
promoter region and nephrin expression [40]. Similar results have shown in brain neurons that DNMT1 and DNMT3A play an essential coordinately role on memory formation [72]; however, the precise mechanism has not been clarified. Similar to neurons, maintenance of DNA methylation mediated by the coordinate action of DNMTs may be necessary in podocytes and that epigenetic alterations may occur even in static states. Future investigations are necessary to establish an evident role of maintenance DNA methylation in podocyte function. The association of DNA damage repair with DNA methylation changes in other kidney cells would be revealed in future studies.

The involvement of DNA damage repair in altered DNA methylation may be one of the reasons for site-specific changes in DNA methylation. The frequency of DNA damage depends on the chromatin status of condensation [73-75], and DNA wrapped in nucleosomes is not a good substrate for DNMTs [76-78]. A more relaxed or "open" chromatin conformation is prone to both exogenous and endogenous damages and leads to an enhanced DNA damage response. Therefore, the specificity of changes in DNA methylation may be partially dependent on chromatin accessibility.

\section{Conclusion and Future Perspectives}

Recent advances in the research of the DNA damage repair system, including the discovery of related factors and elucidation of the association with nutrition and metabolism, will help us understand kidney diseases from a new aspect. The importance of the DNA damage repair processes has been mainly investigated in aging. Aging and age-related diseases are caused in part by the accumulation of DNA damage, which is probably due to declining DNA repair capacity as well as ongoing DNA damage induction $[43,79]$. Further studies of DNA damage repair in the kidney may lead to investigating strategies for the protection of renal function against kidney aging as well as kidney diseases.

Moreover, the association of DNA damage repair with altered DNA methylation may provide an explanation of cell-specific or gene-specific changes in DNA methylation in various diseases. We speculate that the specificity may be determined in part by the environment of DNA damage repair, including the chromatin status (open or closed), length of the genes [38], dividing or nondividing conditions, and expression of DNA repair factors. In our experiment, deletion of DNA DSB repair factor KAT5 in podocytes develops massive proteinuria and renal failure, whereas deletion of KAT5 in proximal tubular cells or endothelial cells caused no significant renal manifestations (unpublished data). These results suggest the cellspecific pathway of DNA repair in the kidney. Recent techniques of single-cell analysis may contribute to elucidate kidney cell-specific DNA repair pathway [80]. Park et al. [81] reported gene expression data analyzed by single-cell transcriptomics study in the kidney. There are differences between the gene expressions of DNA repair factors in each cell type. Future study may reveal the relationship between different expression of DNA repair factors and kidney phenotypes of diseases.

To apply epigenetic therapy for kidney disease, focusing on the mechanism of cell-specific epigenetic changes is important for preventing side effects. Remodeling of cell-specific epigenetic status that is altered in pathophysiological conditions may become novel therapeutic approach for CKD. DNMT inhibitors and histone deacetylase inhibitors are available for clinical use in hematological malignancies; however, there are concerns about the side effects of applying these drugs for kidney diseases. The association of the DNA repair system with epigenetic alterations may suggest a novel approach, targeting the kidney epigenome. In general, numerous ethical issues are expected to be raised by epigenetic modulation for therapy. Because epigenome is heritable, epigenetic changes caused in gamete formation may affect the next generations. Careful discussion is necessary especially in considering the application for persons with future reproduction.

Transcription factors may also be good candidates because the specificity of epigenetic modulation is determined in part by a combination of transcription factors and epigenetic modifiers, which often form a complex $[82,83]$. It has been reported that the transcription factor Kruppel-like factor 4 mediates gene-specific epigenetic regulation in podocytes, which is associated with the renin angiotensin system and CKD progression $[61,62]$. Investigation of the epigenetic-modifying complex, including Kruppel-like factor4, in podocytes may be helpful for the development of epigenetic therapy for CKD. For applying transcription factors as therapeutic targets, to investigate the molecules acting as activators, inducers or stabilizer of the transcription factors may be one of the approaches, such as Nrf2 $[84,85]$ and hypoxia-inducible factor $[86,87]$. The pleiotropic effects of transcription factors may sometimes be harmful in clinical use, as transcription factors often regulate multiple target genes. To reduce the side effects, it is necessary to explore specific 
induction pathways in a particular tissue or cell type and to develop a novel drug delivery system to the specific target cells.

DNA damage repair and altered epigenetic regulation have been infrequently reported together; however, the possible relationship of these systems may contribute to a novel approach against kidney aging and diseases. Future investigations about the environment of DNA damage repair and epigenetic alterations in the kidney are needed.

\section{Acknowledgments}

This work was supported by Grants for Scientific Research (16K19496) from the Ministry of Education, Culture, Sports, Science, and Technology (MEXT) of Japan and Grants for female researchers from the Naito Memorial Foundation.

\section{Disclosure Statement}

The authors declare no conflicts of interest related to this study.

\section{References}

1 López-Otín C, Blasco MA, Partridge L, Serrano M, Kroemer G. The hallmarks of aging. Cell. 2013 Jun;153(6):1194-217.

2 Lieber MR. The mechanism of double-strand DNA break repair by the nonhomologous DNA end-joining pathway. Annu Rev Biochem. 2010;79(1):181-211.

3 Shimizu I, Yoshida Y, Suda M, Minamino T. DNA damage response and metabolic disease. Cell Metab. 2014 Dec;20(6):967-77.

4 Hoeijmakers JH. DNA damage, aging, and cancer. N Engl J Med. 2009 Oct;361(15): 1475-85.

5 Berkovich E, Monnat RJ Jr, Kastan MB. Roles of ATM and NBS1 in chromatin structure modulation and DNA double-strand break repair. Nat Cell Biol. 2007 Jun;9(6): 683-90.

6 Mladenov E, Iliakis G. Induction and repair of DNA double strand breaks: the increasing spectrum of non-homologous end joining pathways. Mutat Res. 2011 Jun;711(1-2):6172.

7 Kunz C, Saito Y, Schär P. DNA Repair in mammalian cells: Mismatched repair: variations on a theme. Cell Mol Life Sci. 2009 Mar; 66(6):1021-38

8 Robertson AB, Klungland A, Rognes T, Leiros I. DNA repair in mammalian cells: Base excision repair: the long and short of it. Cell Mol Life Sci. 2009 Mar;66(6):981-93.

9 Nouspikel T. DNA repair in mammalian cells: Nucleotide excision repair: variations on versatility. Cell Mol Life Sci. 2009 Mar;66(6): 994-1009.

10 Marteijn JA, Lans H, Vermeulen W, Hoeijmakers JH. Understanding nucleotide excision repair and its roles in cancer and ageing. Nat Rev Mol Cell Biol. 2014 Jul;15(7):46581.

11 Schermer B, Bartels V, Frommolt P, Habermann B, Braun F, Schultze JL, et al. Transcriptional profiling reveals progeroid $\operatorname{Erccl}(-/ \Delta)$ mice as a model system for glomerular aging. BMC Genomics. 2013 Aug; 14(1):559.

12 Burtner CR, Kennedy BK. Progeria syndromes and ageing: what is the connection?
Nat Rev Mol Cell Biol. 2010 Aug;11(8):56778.

13 Kipling D, Davis T, Ostler EL, Faragher RG. What can progeroid syndromes tell us about human aging? Science. 2004 Sep;305(5689): 1426-31.

14 Selfridge J, Hsia KT, Redhead NJ, Melton DW. Correction of liver dysfunction in DNA repair-deficient mice with an ERCC1 transgene. Nucleic Acids Res. 2001 Nov;29(22): 4541-50.

15 Weren RD, Ligtenberg MJ, Kets CM, de Voer RM, Verwiel ET, Spruijt L, et al. A germline homozygous mutation in the base-excision repair gene NTHL1 causes adenomatous polyposis and colorectal cancer. Nat Genet. 2015 Jun;47(6):668-71.

16 Bougeard G, Olivier-Faivre L, Baert-Desurmont S, Tinat J, Martin C, Bouvignies E, et al. Diversity of the clinical presentation of the MMR gene biallelic mutations. Fam Cancer. 2014 Mar;13(1):131-5.

17 Woodbine L, Gennery AR, Jeggo PA. The clinical impact of deficiency in DNA non-homologous end-joining. DNA Repair (Amst). 2014 Apr;16:84-96.

18 Murray JE, van der Burg M, IJspeert H, Carroll $\mathrm{P}, \mathrm{Wu} \mathrm{Q}, \mathrm{Ochi} \mathrm{T}$, et al. Mutations in the NHEJ component XRCC4 cause primordial dwarfism. Am J Hum Genet. 2015 Mar;96(3):412-24.

19 Guo C, Nakazawa Y, Woodbine L, Björkman A, Shimada M, Fawcett H, et al. XRCC4 deficiency in human subjects causes a marked neurological phenotype but no overt immunodeficiency. J Allergy Clin Immunol. 2015 Oct;136(4):1007-17.

20 Reiling E, Dollé ME, Youssef SA, Lee M, Nagarajah $\mathrm{B}$, Roodbergen $\mathrm{M}$, et al. The progeroid phenotype of Ku80 deficiency is dominant over DNA-PKCS deficiency. PLoS One. 2014 Apr;9(4):e93568.

21 Weemaes CM, Smeets DF, Horstink M, Haraldsson A, Bakkeren JA. Variants of Nijmegen breakage syndrome and ataxia telangiectasia. Immunodeficiency. 1993;4(1-4): 109-11.

22 Chaki M, Airik R, Ghosh AK, Giles RH, Chen $\mathrm{R}$, Slaats GG, et al. Exome capture reveals
ZNF423 and CEP164 mutations, linking renal ciliopathies to DNA damage response signaling. Cell. 2012 Aug;150(3):533-48.

23 Airik R, Slaats GG, Guo Z, Weiss AC, Khan $\mathrm{N}$, Ghosh A, et al. Renal-retinal ciliopathy gene Sdccag8 regulates DNA damage response signaling. J Am Soc Nephrol. 2014 Nov;25(11):2573-83.

24 Jain M, Kaiser RW, Bohl K, Hoehne M, Göbel $\mathrm{H}$, Bartram MP, et al. Inactivation of Apoptosis Antagonizing Transcription Factor in tubular epithelial cells induces accumulation of DNA damage and nephronophthisis. Kidney Int. 2019 Apr;95(4):846-58.

25 Yesil-Devecioglu T, Dayan A, Demirtunc R, Sardas S. Role of DNA repair genes XRCC3 and XRCC 1 in predisposition to type 2 diabetes mellitus and diabetic nephropathy. Endocrinol Diabetes Nutr. 2019 Feb;66(2):908.

26 Susa D, Mitchell JR, Verweij M, van de Ven $\mathrm{M}$, Roest $\mathrm{H}$, van den Engel S, et al. Congenital DNA repair deficiency results in protection against renal ischemia reperfusion injury in mice. Aging Cell. 2009 Apr;8(2):192200.

27 Limpose KL, Trego KS, Li Z, Leung SW, Sarker AH, Shah JA, et al. Overexpression of the base excision repair NTHL1 glycosylase causes genomic instability and early cellular hallmarks of cancer. Nucleic Acids Res. 2018 May;46(9):4515-32.

28 Schupp N, Queisser N, Wolf M, Kolkhof P, Bärfacker L, Schäfer S, et al. Aldosterone causes DNA strand breaks and chromosomal damage in renal cells, which are prevented by mineralocorticoid receptor antagonists. Horm Metab Res. 2010 Jun;42(6): 458-65.

29 Schmid U, Stopper H, Schweda F, Queisser N, Schupp N. Angiotensin II induces DNA damage in the kidney. Cancer Res. 2008 Nov; 68(22):9239-46.

30 Ma Z, Wei Q, Dong G, Huo Y, Dong Z. DNA damage response in renal ischemia-reperfusion and ATP-depletion injury of renal tubular cells. Biochim Biophys Acta. 2014 Jul; 1842(7):1088-96. 
31 Bartz RR, Fu P, Suliman HB, Crowley SD, MacGarvey NC, Welty-Wolf K, et al. Staphylococcus aureus sepsis induces early renal mitochondrial DNA repair and mitochondrial biogenesis in mice. PLoS One. 2014 Jul; 9(7):e100912.

32 Pressly JD, Park F. DNA repair in ischemic acute kidney injury. Am J Physiol Renal Physiol. 2017 Apr;312(4):F551-5.

33 Yan M, Tang C, Ma Z, Huang S, Dong Z. DNA damage response in nephrotoxic and ischemic kidney injury. Toxicol Appl Pharmacol. 2016 Dec;313:104-8.

34 Marshall CB, Pippin JW, Krofft RD, Shankland SJ. Puromycin aminonucleoside induces oxidant-dependent DNA damage in podocytes in vitro and in vivo. Kidney Int. 2006 Dec;70(11):1962-73.

35 Krüger K, Thomale J, Stojanović N, Osmak $\mathrm{M}$, Henninger $\mathrm{C}$, Bormann S, et al. Platinuminduced kidney damage: unraveling the DNA damage response (DDR) of renal tubular epithelial and glomerular endothelial cells following platinum injury. Biochim Biophys Acta. 2015 Mar;1853(3):685-98.

36 Yang Y, Liu H, Liu F, Dong Z. Mitochondrial dysregulation and protection in cisplatin nephrotoxicity. Arch Toxicol. 2014 Jun;88(6) 1249-56.

37 Dalgliesh GL, Furge K, Greenman C, Chen L, Bignell G, Butler A, et al. Systematic sequencing of renal carcinoma reveals inactivation of histone modifying genes. Nature. 2010 Jan; 463(7279):360-3.

38 Vermeij WP, Dollé ME, Reiling E, Jaarsma D, Payan-Gomez C, Bombardieri CR, et al. Restricted diet delays accelerated ageing and genomic stress in DNA-repair-deficient mice. Nature. 2016 Sep;537(7620):427-31.

39 Rai P, Singh T, Lederman R, Chawla A, Kumar D, Cheng K, et al. Hyperglycemia enhances kidney cell injury in HIVAN through down-regulation of vitamin $D$ receptors. Cell Signal. 2015 Mar;27(3):460-9.

40 Hishikawa A, Hayashi K, Abe T, Kaneko M, Yokoi H, Azegami T, et al. Decreased KAT5 expression impairs DNA repair and induces altered DNA methylation in kidney podocytes. Cell Rep. 2019 Jan;26(5):1318-1332.e4.

41 Schneider JG, Finck BN, Ren J, Standley KN, Takagi M, Maclean KH, et al. ATM-dependent suppression of stress signaling reduces vascular disease in metabolic syndrome. Cell Metab. 2006 Nov;4(5):377-89.

42 Matsuoka S, Ballif BA, Smogorzewska A, McDonald ER 3rd, Hurov KE, Luo J, et al. ATM and ATR substrate analysis reveals extensive protein networks responsive to DNA damage. Science. 2007 May;316(5828):1160-6.

43 Jackson SP, Bartek J. The DNA-damage response in human biology and disease. Nature. 2009 Oct;461(7267):1071-8

44 Mortusewicz O, Schermelleh L, Walter J, Cardoso MC, Leonhardt H. Recruitment of DNA methyltransferase I to DNA repair sites. Proc Natl Acad Sci USA. 2005 Jun; 102(25):8905-9.
45 Benayoun BA, Pollina EA, Brunet A. Epigen etic regulation of ageing: linking environmental inputs to genomic stability. Nat Rev Mol Cell Biol. 2015 Oct;16(10):593-610.

46 Orlowski C, Mah LJ, Vasireddy RS, El-Osta A, Karagiannis TC. Double-strand breaks and the concept of short- and long-term epigenetic memory. Chromosoma. 2011 Apr;120(2): $129-49$.

47 Cuozzo C, Porcellini A, Angrisano T, Morano A, Lee B, Di Pardo A, et al. DNA damage, homology-directed repair, and DNA methylation. PLoS Genet. 2007 Jul;3(7):e110.

48 O'Hagan HM, Mohammad HP, Baylin SB. Double strand breaks can initiate gene silencing and SIRT1-dependent onset of DNA methylation in an exogenous promoter $\mathrm{CpG}$ island. PLoS Genet. 2008 Aug;4(8):e1000155.

49 Fatemi M, Hermann A, Pradhan S, Jeltsch A. The activity of the murine DNA methyltransferase Dnmt1 is controlled by interaction of the catalytic domain with the $\mathrm{N}$-terminal part of the enzyme leading to an allosteric activation of the enzyme after binding to methylated DNA. J Mol Biol. 2001 Jun;309(5):118999.

50 Vilkaitis G, Suetake I, Klimasauskas S, Tajima S. Processive methylation of hemimethylated CpG sites by mouse Dnmt1 DNA methyltransferase. J Biol Chem. 2005 Jan;280(1):6472.

51 Goyal R, Reinhardt R, Jeltsch A. Accuracy of DNA methylation pattern preservation by the Dnmt1 methyltransferase. Nucleic Acids Res. 2006 Feb;34(4):1182-8.

52 Fatemi M, Hermann A, Gowher H, Jeltsch A. Dnmt3a and Dnmt1 functionally cooperate during de novo methylation of DNA. Eur J Biochem. 2002 Oct;269(20):4981-4.

53 Kim GD, Ni J, Kelesoglu N, Roberts RJ, Pradhan S. Co-operation and communication between the human maintenance and de novo DNA (cytosine-5) methyltransferases. EMBO J. 2002 Aug;21(15):4183-95.

54 Reddy MA, Natarajan R. Recent developments in epigenetics of acute and chronic kidney diseases. Kidney Int. 2015 Aug; 88(2): 250-61.

55 Pattaro C, Teumer A, Gorski M, Chu AY, Li M, Mijatovic V, et al.; ICBP Consortium; AGEN Consortium; CARDIOGRAM; CHARGe-Heart Failure Group; ECHOGen Consortium. Genetic associations at 53 loci highlight cell types and biological pathways relevant for kidney function. Nat Commun. 2016 Jan;7(1):10023.

56 Sapienza C, Lee J, Powell J, Erinle O, Yafai F, Reichert J, et al. DNA methylation profiling identifies epigenetic differences between diabetes patients with ESRD and diabetes patients without nephropathy. Epigenetics. 2011 Jan;6(1):20-8.

57 Wing MR, Devaney JM, Joffe MM, Xie D, Feldman HI, Dominic EA, et al.; Chronic Renal Insufficiency Cohort (CRIC) Study. DNA methylation profile associated with rapid decline in kidney function: findings from the
CRIC study. Nephrol Dial Transplant. 2014 Apr;29(4):864-72.

58 Smyth LJ, McKay GJ, Maxwell AP, McKnight AJ. DNA hypermethylation and DNA hypomethylation is present at different loci in chronic kidney disease. Epigenetics. 2014 Mar;9(3):366-76.

59 Chu AY, Tin A, Schlosser P, Ko YA, Qiu C, Yao $\mathrm{C}$, et al. Epigenome-wide association studies identify DNA methylation associated with kidney function. Nat Commun. 2017 Nov;8(1):1286.

60 Ko YA, Mohtat D, Suzuki M, Park AS, Izquierdo MC, Han SY, et al. Cytosine methylation changes in enhancer regions of core pro-fibrotic genes characterize kidney fibrosis development. Genome Biol. 2013;14(10):R108.

61 Hayashi K, Sasamura H, Nakamura M, Azegami T, Oguchi H, Sakamaki Y, et al. KLF4dependent epigenetic remodeling modulates podocyte phenotypes and attenuates proteinuria. J Clin Invest. 2014 Jun;124(6):2523-37.

62 Hayashi K, Sasamura H, Nakamura M, Sakamaki Y, Azegami T, Oguchi H, et al. Reninangiotensin blockade resets podocyte epigenome through Kruppel-like Factor 4 and attenuates proteinuria. Kidney Int. 2015 Oct; 88(4):745-53.

63 Zhang L, Zhang Q, Liu S, Chen Y, Li R, Lin T, et al. DNA methyltransferase 1 may be a therapy target for attenuating diabetic nephropathy and podocyte injury. Kidney Int. $2017 \mathrm{Jul}$; 92(1):140-53.

64 Ristola M, Arpiainen S, Saleem MA, Holthöfer $\mathrm{H}$, Lehtonen S. Transcription of nephrinNeph3 gene pair is synergistically activated by WT1 and NF- $\kappa B$ and silenced by DNA methylation. Nephrol Dial Transplant. 2012 May; 27(5):1737-45.

65 Hamatani H, Sakairi T, Ikeuchi H, Kaneko Y, Maeshima A, Nojima Y, et al. TGF- $\beta 1$ alters DNA methylation levels in promoter and enhancer regions of the WT1 gene in human podocytes. Nephrology (Carlton). 2019 May; 24(5):575-84.

66 Wanner N, Hartleben B, Herbach N, Goedel M, Stickel N, Zeiser R, et al. Unraveling the role of podocyte turnover in glomerular aging and injury. J Am Soc Nephrol. 2014 Apr: 25(4):707-16.

67 Shankland SJ, Pippin JW, Duffield JS. Progenitor cells and podocyte regeneration. Semin Nephrol. 2014 Jul;34(4):418-28.

68 Nagata M. Podocyte injury and its consequences. Kidney Int. 2016 Jun;89(6):1221-30.

69 Lieber MR, Ma Y, Pannicke U, Schwarz K. Mechanism and regulation of human nonhomologous DNA end-joining. Nat Rev Mol Cell Biol. 2003 Sep;4(9):712-20.

70 Cann KL, Dellaire G. Heterochromatin and the DNA damage response: the need to relax. Biochem Cell Biol. 2011 Feb;89(1):45-60.

71 Li SY, Park J, Guan Y, Chung K, Shrestha R, Palmer MB, et al. DNMT1 in Six2 Progenitor Cells Is Essential for Transposable Element Silencing and Kidney Development. J Am Soc Nephrol. 2019 Apr;30(4):594-609. 
72 Feng J, Zhou Y, Campbell SL, Le T, Li E, Sweatt JD, et al. Dnmt1 and Dnmt3a maintain DNA methylation and regulate synaptic function in adult forebrain neurons. Nat Neurosci. 2010 Apr;13(4):423-30.

73 Cowell IG, Sunter NJ, Singh PB, Austin CA, Durkacz BW, Tilby MJ. gammaH2AX foci form preferentially in euchromatin after ionising-radiation. PLoS One. 2007 Oct;2(10): e1057.

74 Kim JA, Kruhlak M, Dotiwala F, Nussenzweig A, Haber JE. Heterochromatin is refractory to gamma-H2AX modification in yeast and mammals. J Cell Biol. 2007 Jul;178(2):209-18.

75 Takata H, Hanafusa T, Mori T, Shimura M, Iida $\mathrm{Y}$, Ishikawa $\mathrm{K}$, et al. Chromatin compaction protects genomic DNA from radiation damage. PLoS One. 2013 Oct;8(10):e75622.

76 Robertson AK, Geiman TM, Sankpal UT, Hager GL, Robertson KD. Effects of chromatin structure on the enzymatic and DNA binding functions of DNA methyltransferases DNMT1 and Dnmt3a in vitro. Biochem Biophys Res Commun. 2004 Sep;322(1):110-8.

77 Takeshima H, Suetake I, Shimahara H, Ura K, Tate S, Tajima S. Distinct DNA methylation activity of Dnmt3a and Dnmt3b towards naked and nucleosomal DNA. J Biochem. 2006 Mar;139(3):503-15.

78 Takeshima H, Suetake I, Tajima S. Mouse Dnmt3a preferentially methylates linker DNA and is inhibited by histone H1. J Mol Biol. 2008 Nov;383(4):810-21.

79 Schumacher B, Garinis GA, Hoeijmakers JH. Age to survive: DNA damage and aging. Trends Genet. 2008 Feb;24(2):77-85.

$80 \mathrm{Wu} \mathrm{H}$, Humphreys BD. The promise of single-cell RNA sequencing for kidney disease investigation. Kidney Int. 2017 Dec;92(6): 1334-42.
81 Park J, Shrestha R, Qiu C, Kondo A, Huang S, Werth M, et al. Single-cell transcriptomics of the mouse kidney reveals potential cellular targets of kidney disease. Science. 2018 May; 360(6390):758-63.

82 Hishikawa A, Hayashi K, Itoh H. Transcription Factors as Therapeutic Targets in Chronic Kidney Disease. Molecules. 2018 May; 23(5):23.

83 Hayashi K, Hishikawa A, Itoh H. DNA Damage and Epigenetic Changes in Kidney Diseases - Focused on Transcription Factors in Podocytes. Curr Hypertens Rev. 2016;12(2): 105-11.

84 Dinkova-Kostova AT, Liby KT, Stephenson KK, Holtzclaw WD, Gao X, Suh N, et al. Extremely potent triterpenoid inducers of the phase 2 response: correlations of protection against oxidant and inflammatory stress. Proc Natl Acad Sci USA. 2005 Mar;102(12):45849.

85 Ruiz S, Pergola PE, Zager RA, Vaziri ND. Targeting the transcription factor Nrf2 to ameliorate oxidative stress and inflammation in chronic kidney disease. Kidney Int. 2013 Jun; 83(6):1029-41.

86 Tanaka T, Matsumoto M, Inagi R, Miyata T, Kojima I, Ohse T, et al. Induction of protective genes by cobalt ameliorates tubulointerstitial injury in the progressive Thyl nephritis. Kidney Int. 2005 Dec;68(6):2714-25.

87 Tanaka T, Kojima I, Ohse T, Inagi R, Miyata $T$, Ingelfinger JR, et al. Hypoxia-inducible factor modulates tubular cell survival in cisplatin nephrotoxicity. Am J Physiol Renal Physiol. 2005 Nov;289(5):F1123-33.

88 Ben Chehida A, Ghali N, Ben Abdelaziz R, Ben Moussa F, Tebib N. Renal Involvement in 2 Siblings With Cockayne Syndrome. Iran J Kidney Dis. 2017 May;11(3):253-5.
89 Hirooka M, Hirota M, Kamada M. Renal lesions in Cockayne syndrome. Pediatr Nephrol. 1988 Apr;2(2):239-43.

90 Kralund HH, Ousager L, Jaspers NG, Raams A, Pedersen EB, Gade E, et al. Xeroderma Pigmentosum-Trichothiodystrophy overlap patient with novel XPD/ERCC2 mutation. Rare Dis. 2013 May; 1(1):e24932.

91 Aracil M, Dauffenbach LM, Diez MM, Richeh R, Moneo V, Leal JF, et al. Expression of XPG protein in human normal and tumor tissues. Int J Clin Exp Pathol. 2013;6(2):199-211.

92 Kondo D, Noguchi A, Tamura H, Tsuchida S, Takahashi I, Kubota H, et al. Elevated Urinary Levels of 8-Hydroxy-2'-deoxyguanosine in a Japanese Child of Xeroderma Pigmentosum/ Cockayne Syndrome Complex with Infantile Onset of Nephrotic Syndrome. Tohoku J Exp Med. 2016 Jul;239(3):231-5.

93 Sathyanarayana V, Lee B, Wright NB, Santos $\mathrm{R}$, Bonney D, Wynn R, et al. Patterns and frequency of renal abnormalities in Fanconi anaemia: implications for long-term management. Pediatr Nephrol. 2018 Sep;33(9):1547-51.

94 Zhou W, Otto EA, Cluckey A, Airik R, Hurd TW, Chaki M, et al. FAN1 mutations cause karyomegalic interstitial nephritis, linking chronic kidney failure to defective DNA damage repair. Nat Genet. 2012 Jul;44(8):910-5.

95 Alanee S, Shah S, Murali R, Rau-Murthy R, Schrader KA, Offit K. Absence of loss of heterozygosity of BRCA1 in a renal tumor from a BRCA1 germline mutation carrier. Fam Cancer. 2013 Mar;12(1):125-7.

96 Kroeger PT Jr, Drummond BE, Miceli R, McKernan M, Gerlach GF, Marra AN, et al. The zebrafish kidney mutant zeppelin reveals that brca2/fancd1 is essential for pronephros development. Dev Biol. 2017 Aug;428(1): 148-63. 